\title{
Mononuclear Cells From Human Lung Parenchyma Support Antigen-Induced T Lymphocyte Proliferation
}

\author{
Laurent P. Nicod, Mary F. Lipscomb, Jonathan C. Weissler, and Galen B. Toews \\ Departments of Internal Medicine (L.P.N., J.C.W., G.B.T.) and Pathology (M.F.L.), The University of Texas Health Science \\ Center at Dallas, Dallas
}

\begin{abstract}
We have previously demonstrated that there is a subpopulation of loosely adherent pulmonary mononuclear cells that can be isolated from minced and enzyme-digested lung tissue with a potent capacity to stimulate allogeneic T lymphocyte proliferation. We now demonstrate that these cells are also capable of stimulating an autologous mixed leukocyte reaction (AMLR) and presenting antigen to autologous $T$ lymphocytes. These loosely adherent mononuclear cells (LAM) were more effective than either alveolar macrophages or monocytes as antigen-presenting cells. Depletion of phagocytic or Fc receptor-positive cells from the LAM population enhanced the stimulation of an reaction AMLR while preserving antigen-induced $T$ lymphocyte proliferation. These results indicate that there are nonphagocytic, Fc receptor-negative accessory cells in human lung parenchyma capable of activating resting $T$ cells in an AMLR and supporting antigenspecific T lymphocyte proliferation. The identity of these cells is uncertain, but the data strongly suggest that the cell is not a classical monocyte-derived macrophage. These antigen-presenting cells may be critical in the initiation of immune responses within the lung.
\end{abstract}

Key words: antigen presentation, human lung, pulmonary interstitium

\section{INTRODUCTION}

The expression of an immune response within the lung is essential to enhance a host's capacity to clear certain infectious agents $[1,10]$. Immune responses develop in hilar lymph nodes [17] in response to antigens delivered to the lung via the tracheobronchial tree. Whether immunity can be initiated in the parenchyma of the lung is still controversial $[15,25]$. However, the involvement of the pulmonary interstitium in diseases such as hypersensitivity pneumonitis [20] or sarcoidosis [14] suggests that under certain circumstances cellular and/or humoral immune responses occur in the interstitium of human lung.

The generation of an immune response requires the activation of $T$ lymphocytes by an antigen-presenting cell (APC) which must express class II major histocompatibility antigens $[11,38]$. Previous studies attempting to identify an APC in the lung examined alveolar macrophages (AM) obtained by bronchoalveolar lavage. The majority of previous studies demonstrated that AM collected from most normal volunteers are poor stimulators of antigen-induced $\mathrm{T}$ lymphocyte proliferation when compared to peripheral blood monocytes (Mo) $[6,16$, $37,40,41]$.

We have recently isolated a population of pulmonary mononuclear cells (PMC) from enzymatically digested human lung tissue which were potent stimulators of an allogeneic mixed leukocyte reaction (MLR) [29]. Accessory cell function was significantly enriched in a loosely adherent population of PMC, suggesting that loosely adherent mononuclear cells (LAM) in human lung parenchyma might present soluble antigen. However, some authors have suggested that the ability of an accessory cell to stimulate a MLR may not correlate with presentation of soluble antigen $[28,31]$. Indeed, in a prior study from our laboratory PMC from mechanically digested

Received August 3, 1988; accepted November 21, 1988.

Galen B. Toews is now at Department of Internal Medicine, University of Michigan, Ann Arbor, MI. 48109.

Laurent P. Nicod is now at Department of Internal Medicine, Hopital Cantonal de Geneva, 1211 Geneva, Switzerland.

Jonathan C. Weissler is the recipient of Clinical Investigator Award HL 01797.

Reprint requests: Jonathan C. Weissler, M.D., Department of Internal Medicine, Pulmonary Division, University of Texas Southwestern Medical Center, Dallas, TX 75235-9034. 
lung tissue stimulated an MLR but did not present antigen [41].

The purpose of the current study was to determine whether PMC from minced and enzyme-digested lung could present soluble antigen to autologous peripheral blood $\mathrm{T}$ lymphocytes. In contrast to previous studies using mechanical digestion alone, PMC were more effective in presenting antigen than AM. Further enrichment of APC was obtained in the loosely adherent population of cells (LAM), and APC function was maintained following depletion of either Fc receptorpositive $(\mathrm{FcR}+)$ cells or phagocytic cells, suggesting that the APC was not a classical macrophage. These results demonstrate that there are mononuclear cells in human lung parenchyma capable of inducing antigenspecific lymphoproliferation in response to foreign antigen.

\section{MATERIALS AND METHODS Subjects}

Grossly normal pulmonary tissue was obtained from surgical specimens resected from patients with primary lung carcinoma. To isolate lymphocytes and monocytes, $90 \mathrm{ml}$ of blood was drawn. Four patients also underwent bronchoalveolar lavage at the time of thoracatomy after their informed consent was obtained. All patients were smokers. No patient had clinical evidence of active pulmonary infection at the time of surgery.

\section{Preparation of Cells From Lung}

Bronchoalveolar lavage was performed in a lobe adjacent to the lobe to be resected using a total of $200 \mathrm{ml}$ of $0.9 \%$ normal saline as previously described [37]. Cells from bronchoalveolar lavage (BAL) were washed twice with Hanks' balanced salt solution (HBSS; Microbiological Associates, Walker, MD). The cells were resuspended in complete medium (RPMI 1640 with 25 mM HEPES (Inland Laboratory, Austin, TX), $2 \mathrm{mM}$ glutamine, $100 \mu \mathrm{g} / \mathrm{ml}$ penicillin, $100 \mu \mathrm{g} / \mathrm{ml}$ streptomycin (all from Gibco Laboratories, Grand Island, NY), and $24 \mu \mathrm{g} / \mathrm{ml}$ gentamicin (Elkins-Sinn, Cherry Hill, NJ)) plus $20 \%$ heat, inactivated pooled human serum (HS). Viability was assessed by trypan blue exclusion and was greater than $95 \%$. BAL consisted of more than $90 \%$ large cells with complex cytoplasm consistent with AM. It has been previously shown that isolating AM from BAL does not change their inability to present antigen or stimulate an MLR [37].

The lung specimen was initially lightly pressed and rinsed with HBSS to remove residual blood. PMC were obtained from whole lung by mincing the $30 \mathrm{~g}$ of tissue with scissors in a petri dish filled with complete medium. The lung fragments were digested as reported previously
[29] with Type I collagenase (150 units/ml) and Type IIA elastase (10 units/ml, both from Sigma Chemical Co, St. Louis, MO) for $90 \mathrm{~min}$. The enzyme-digested lung was then tapped gently through a stainless steel screen to dissociate the tissue into single cells. A Ficoll-Hypaque gradient (Ficoll from Sigma Chemical Co., St. Louis, MO; Hypaque from Winthrop-Breon, New York, NY) was used to separate the dissociated cells. The pulmonary mononuclear cells at the interface were washed three times in HBSS. Viability was assessed by trypan blue and was $>90 \%$. Differential counts were performed on Wright-stained smears: $70-75 \%$ were macrophagelike; $20-25 \%$ were lymphocytes. To evaluate the contamination of PMC by blood mononuclear cells, the number of blood mononuclear cells/g of hemoglobin in peripheral blood and the hemoglobin content of the lung digests was determined. The number of blood mononuclear cells in the lung cell population was determined by multiplying the lung digest hemoglobin by the number of mononuclear cells/g of hemoglobin in peripheral blood. Maximal contamination of PMC by peripheral blood cells averaged $3 \%$ (range $1-8 \%$ ).

PMC were fractionated into low-density, loosely adherent fractions of mononuclear cells (LAM) and firmly adherent mononuclear cells (FAM) according to the method of VanVoorhis et al. [39]. Briefly, 150-350 $\times$ $10^{6}$ cells were incubated in complete medium containing $10 \%$ heat-inactivated fetal calf serum (FCS, Gibco Laboratories, Chagrin Falls, OR), on 100-mm tissue culture dishes (Corning Glass Works, Corning, NY) in aliquots of $15-20 \times 10^{6}$ cells/dish at $37^{\circ} \mathrm{C}$. The nonadherent cells were removed after $1 \mathrm{~h}$ with three rinses of HBSS. Nonadherent cells represented half of the PMC; $30-40 \%$ were lymphocytes, $10-20 \%$ were unidentifiable cells, and the remaining cells were mostly macrophages as determined by Wright-stained cytocentrifuge smear preparations. The adherent PMC were incubated for an additional $14-16 \mathrm{~h}$ at $37^{\circ} \mathrm{C}$ in complete medium with $10 \%$ FCS. About half of the cells failed to remain adherent after three rinses with HBSS. These cells were recultured on plastic culture dishes for $1 \mathrm{~h}$. About one-third of the cells readhered and the remainder were removed by washing with HBSS. These loosely adherent, twice released cells were resuspended in complete medium and floated on bovine plasma albumin of density of $1.080 \mathrm{~g} / \mathrm{ml}$ (Pentese; Miles Lab, Naperville, IL). After centrifugation at $10,000 \mathrm{~g}$ for $15 \mathrm{~min}$ at $4^{\circ} \mathrm{C}$ the low-density fraction cells at the interface were harvested. These cells are referred to as loosely adherent mononuclear cells (LAM).

The population of cells that remained adherent after overnight incubation constituted the firmly adherent mononuclear (FAM) fraction. After an incubation of 30 min at $4^{\circ} \mathrm{C}$ in cold phosphate buffered saline, FAM were 
removed from the dishes by gentle scraping with a rubber policeman.

\section{Preparation of FCR - or FCR + LAM}

Sheep red blood cells (SRBC) were opsonized with subagllutinating doses of rabbit antibody against SRBC (Difco Lab, Detroit, MI) as previously described [35]. To remove FcR + cells, washed, opsonized SRBC (1\%) were mixed with $5-10 \times 10^{6} \mathrm{LAM}$ and gently pelleted at $900 \mathrm{rpm} \times 10 \mathrm{~min}$. After $30 \mathrm{~min}$ of incubation at room temperature, the sediment was gently resuspended. The cell mixture was separated on a Ficoll-Hypaque gradient. Rosetting $(\mathrm{FcR}+)$ and nonrosetting $(\mathrm{FcR}-)$ cells were in the sediment and at the interface, respectively.

\section{Preparation of Nonphagocytic LAM}

Silica particles $(0.1 \mu \mathrm{m})$ were a gift from Dr. K. Rabock, Stein-Kohlenberg-Bauverian, 43 Essen-Krey, West Germany. Two milliliters of LAM at a concentration of $5 \times 10^{6} / \mathrm{ml}$ were mixed with $250 \mu \mathrm{g} / \mathrm{ml}$ of silica in $17 \times 100$ polypropylene culture tubes $(2005$, Falcon Plastics Co., Oxnard, CA). The mixture was gently pelleted at $900 \mathrm{rpm} \times 10 \mathrm{~min}$, then incubated for $30 \mathrm{~min}$ at $37^{\circ} \mathrm{C}$. A Ficoll-Hypaque gradient was used to separate the cell/silica mixture. The nonphagocytic or silica negative (Sil-) cells remained at the interface, whereas silica-laden phagocytic cells sedimented to the bottom of the gradient.

\section{Preparation of Peripheral Blood Monocytes and Lymphocytes}

Peripheral blood mononuclear cells (PBM) from lung donors were obtained on a Ficoll-Hypaque gradient and washed $3 \times$ in HBSS. Monocytes (Mo) were isolated by adhesion on plastic culture dishes. The nonadherent cells, mostly lymphocytes, were removed by washing $3 \times$ with HBSS. Adherent cells were recovered by adding $10 \mathrm{mM}$ ethylenediaminetetraacetic acid (EDTA), reincubating at $37^{\circ} \mathrm{C}$ for $45 \mathrm{~min}$, and removing the cells by washing $3 \times$ in HBSS. Lymphocytes were further depleted of accessory cells with $5.0 \mathrm{mM}$ L-leucine methyl ester as previously described [22]. T cells were rosetted with 2-aminoethylisothiouronium bromidetreated (AET) SRBC at $4^{\circ} \mathrm{C}$ followed by sedimentation through Ficoll-Hypaque. After lysis of SRBC with 0.15 $\mathrm{M} \mathrm{NH}_{4} \mathrm{Cl}$, the lymphocytes were passed through a nylon wool column to remove residual B lymphocytes and Mo. Lastly, T cells were treated with anti-HLA-DR (L243) and baby rabbit complement as previously described [29].

\section{Antigen-Induced T Lymphocyte Proliferation Assay}

Cultures were performed in triplicate in flat-bottomed microtiter plates in $200 \mu \mathrm{l}$ of complete medium with
$20 \%$ HS. Purified T cells $\left(10^{5}\right)$ were cultured alone or with various numbers of accessory cells. AM, Mo, PMC, FAM, LAM, FcR + , FcR - , and Sil- cells were irradiated $(4,500$ rads $)$ in a cesium source. Cultures were incubated for 6 days in $5 \% \mathrm{CO}_{2}$ without or with soluble antigen in a concentration previously determined to give optimal $T$ cell proliferation. Antigens utilized were soluble mumps antigen (M.A. Bioproducts, Walkersville, MD) at a final dilution of $1: 2$ or tetanus toxoid (Mass. Biologic Laboratories, Boston, MA) at a final dilution of 1:50. Eighteen hours before termination of cultures, $0.5 \mu \mathrm{Ci}{ }^{3} \mathrm{H}$-thymidine $\left({ }^{3} \mathrm{HTdR}\right)$ was added to cultures. Cells were collected with an automated cell harvester and counted in a beta liquid scintillation counter. Data were expressed as $\Delta$ counts per minute (average CPM in wells with antigen-average CPM in wells without antigen) for antigen-induced $T$ cell proliferation and as total CPM in wells without antigen for the autologous mixed leukocyte reaction (AMLR).

\section{Monoclonal Antibodies}

The mouse monoclonal antibodies used were L243 (anti HLA-DR, from cell line 243 originally described by Lampson, et al. [19]); $\mathrm{MO}_{2}$ (anti-Mo antibody initially generated against the cell line macrophage $P_{9}[2]$ ); PAM $_{1}$ (antihuman AM originally described and kindly provided by Dr. R. Todd III et al. [2,18]); DAKO-DRC (antifollicular dendritic cells from cell line R4/23 [Dakopatts, Santa Barbara, CA]); and rabbit anti-Factor VIII antiserum (to detect endothelial cells as previously described [27] from Dakopatts). The endothelial cells used as a positive control for the anti-Factor VIII antiserum were kindly provided by Dr. Morris Ziff (Dallas, TX). Cells $\left(0.25-0.5 \times 10^{6}\right)$ were suspended in $50 \mu \mathrm{l}$ of the relevant monoclonal antibody or anti-arsonate control monoclonal antibody (kindly provided by $\mathrm{Dr}$. Don $\mathrm{Ca}$ pra, Dallas, TX). After incubation for $30 \mathrm{~min}$ at $0^{\circ} \mathrm{C}$, the cell were washed twice in RPMI 1640 media. A fluorescein-labeled $F\left(a b^{\prime}\right)_{2}$ rabbit antimouse IgG (Cooper Biomedical, West Chester, PA) was added for $30 \mathrm{~min}$ at $0^{\circ} \mathrm{C}$. Cells were then washed $3 \times$ in RPMI containing $0.2 \%$ sodium azide. The percentage of positive cells was determined by examining at least 200 cells with a fluorescent microscope equipped with epifluorescence optics.

\section{RESULTS \\ Comparison of BAL and PMC in Supporting Antigen-Induced T Lymphocyte Proliferation}

In previous studies PMC obtained from minced but nonenzymatically digested lung did not stimulate antigen-induced lymphoproliferation any more effectively than BAL or AM isolated from BAL [41]. In order 
TABLE 1. Comparison of BAL and PMC in Supporting Antigen-Induced T Lymphocyte Proliferation"

\begin{tabular}{lcrrc}
\hline & \multicolumn{4}{c}{$\Delta$ CPM } \\
\cline { 2 - 5 } Experiment & $\begin{array}{c}\text { T cells } \\
\text { only }\end{array}$ & $\begin{array}{c}\text { T cells } \\
+ \text { BAL }\end{array}$ & $\begin{array}{c}\text { T cells } \\
+ \text { PMC }\end{array}$ & $\begin{array}{c}\text { PMC/BAL } \\
\text { (ratio) }\end{array}$ \\
\hline $1^{\mathrm{b}}$ & 414 & 3,358 & 11,125 & 3.3 \\
$2^{\mathrm{b}}$ & 50 & 2,534 & 5,211 & 2.0 \\
$3^{\mathrm{b}}$ & 0 & 983 & 4,849 & 4.9 \\
$4^{\mathrm{c}}$ & 814 & 1,303 & 11,976 & 9.2 \\
$5^{\mathrm{c}}$ & 156 & 1,368 & 5,316 & 3.8 \\
\hline
\end{tabular}

"Purified autologous T cells $\left(10^{5}\right)$ were cultured with BAL or PMC $\left(2.5 \times 10^{4}\right)$ both with and without soluble antigen.

'Tetanus was used as the soluble antigen.

cMumps was used as the soluble antigen.

to improve the yield of APC from the interstitium, lungs were minced and digested with collagenase and elastase. PMC obtained after enzymatic digestion supported antigen-induced $T$ lymphocyte proliferation two to five times more effectively than BAL (Table 1). Enzymatic treatment of BAL with collagenase or elastase neither diminished nor enhanced their ability to stimulate an MLR (data not shown). Thus the differences between the PMC and BAL could not be explained by enzymeinduced changes on these cells.

\section{Comparison of PMC, FAM, and LAM in Supporting Antigen-Induced T Lymphocyte Proliferation}

Previous studies demonstrated that stimulation of an MLR was greatest by PMC which were loosely adherent [29]. PMC were divided into firmly adherent mononuclear cells (FAM) and loosely adherent mononuclear cells (LAM). The optimal number of APC was determined using LAM and compared to BAL (Fig. 1). As shown, LAM were more effective than BAL at each dose tested.

PMC, LAM, and FAM were compared as stimulators of a proliferative response to soluble mumps antigen. LAM were significantly more effective than either unfractionated PMC or FAM in supporting antigen-induced T lymphocyte proliferation (Fig. 2). These data showed a significant enrichment of a potent APC in the LAM population. Because the number of macrophages in the LAM and FAM population were likely different, and high numbers of macrophages can suppress $\mathrm{T}$ lymphocyte proliferation $[5,32]$, it was important to compare antigen presentation by PMC, FAM, and LAM over a range of stimulator numbers (Table 2). LAM were significantly more effective in supporting antigeninduced lymphoproliferation at all doses tested. This would suggest that the enhanced ability of LAM to

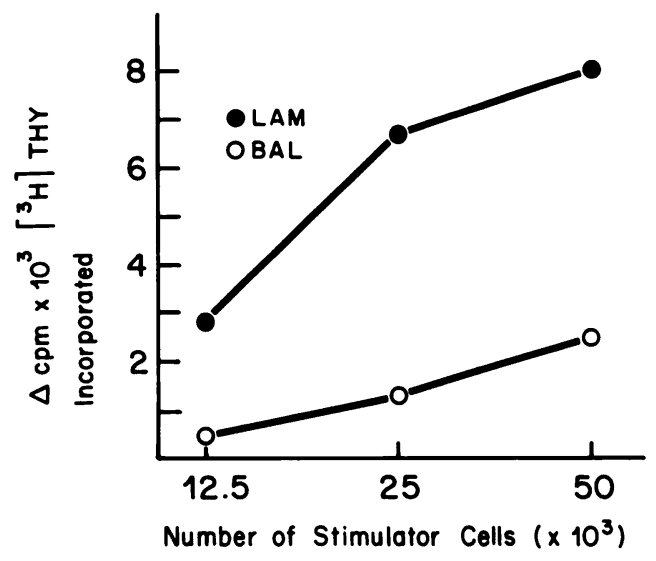

Fig. 1. Dose-reponse curve with BAL (which consist predominantly of AM) and LAM in supporting antigen-induced T lymphocyte proliferation. Autologous $T$ cells $\left(10^{5} /\right.$ well) were cultured in triplicate for 6 days with various numbers of APC.

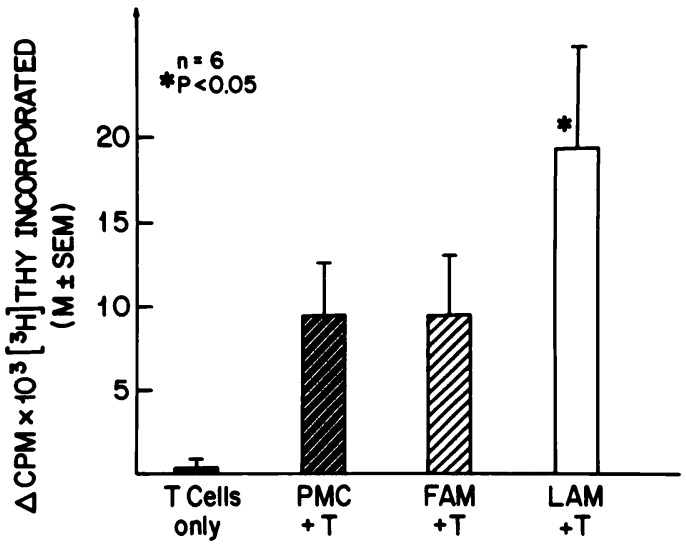

Fig. 2. Comparison of PMC, FAM, and LAM in supporting antigen-induced $T$ lymphocyte proliferation. Autologous $T$ cells $\left(10^{5} /\right.$ well) were cultured in triplicate for 6 days with or without $25 \times 10^{3}$ APC. ${ }^{*} P<0.05$ when LAM are compared to either PMC or FAM by paired Student's t-test.

function as APC cannot be explained solely by the removal of suppressor macrophages.

\section{Comparison of LAM With Mo in Supporting Antigen-Induced T Lymphocyte Proliferation}

While the estimated contamination of PMC by Mo was $<3 \%$, it was possible that immature macrophages (Mo recently arrived from peripheral blood) or Mo from contaminating blood might have been enriched in the LAM fraction. These cells might account for the improved antigen-induced $T$ lymphocyte proliferation. However, in all five experiments, Mo were significantly less effective than LAM (Fig. 3). This suggested that the potent APC present in the LAM fraction was a cell other than Mo. 
TABLE 2. Comparison of PMC, FAM, and LAM in Supporting Antigen-Induced T Lymphocyte Proliferation*

\begin{tabular}{lccc}
\hline & \multicolumn{3}{c}{ Stimulator cell No. $\left(\times 10^{3}\right)$} \\
\cline { 2 - 4 } & 12 & 25 & 50 \\
\hline Experiment 1 & & & \\
PMC & 5,741 & 11,976 & 21,215 \\
FAM & 6,129 & 10,935 & 19,183 \\
LAM & 18,156 & 25,078 & 34,919 \\
Experiment 2 & & & \\
PMC & 3,419 & 5,316 & 15,304 \\
FAM & 1,982 & 6,680 & 13,672 \\
LAM & 9,610 & 14,806 & 25,535 \\
\hline
\end{tabular}

a Purified autologous T cells $\left(10^{5}\right)$ were cultured with PMC, FAM, and LAM with or without mumps antigen. Data are expressed as $\triangle$ CPM $\mathrm{H}^{3}$-thymidine incorporation.

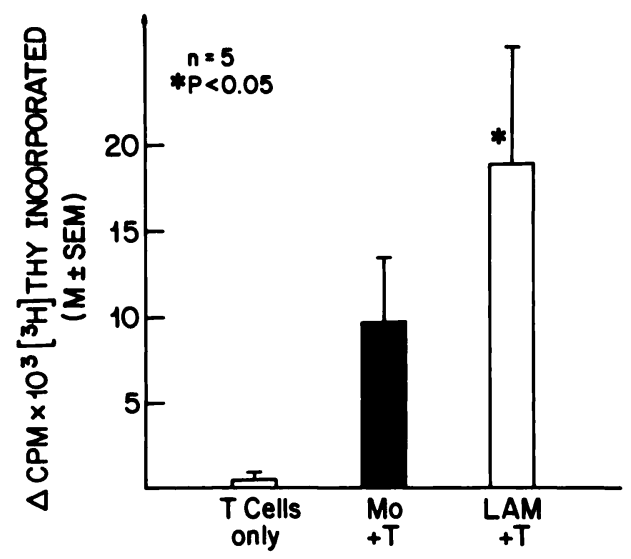

Fig. 3. Comparison of LAM and Mo in supporting antigeninduced $\mathbf{T}$ lymphocyte proliferation. Autologous $\mathbf{T}$ cells (105/well) were cultured in triplicate for 6 days with or without $25 \times 10^{3}$ APC. The antigen used was mumps. The difference between LAM and Mo was significant $(P<0.05)$.

\section{Effect of Depletion of FcR + Macrophages From LAM}

It was possible that the APC present in LAM was a tissue macrophage distinct from either AM or Mo. Because macrophages express FcR on their plasma membranes, it was possible partially to deplete the LAM population of macrophages by rosetting them with rabbit antibody-opsonized SRBC followed by density gradient separation of rosetted and nonrosetted cells. Thus, in previous studies [29] we had demonstrated that stimulation of a MLR was enriched in the FcR - population of cells. FcR + cells were compared with the remaining cells (called FcR -) for their capacity to support antigeninduced $\mathrm{T}$ lymphocyte proliferation. FcR + cells were relatively poor APC compared to FcR - LAM or unfractionated LAM (Fig. 4). This was observed at all stimulator ratios tested $(1: 8,1: 4)$. The antigen-specific $T$ cell proliferation produced in cultures containing FcR - cells

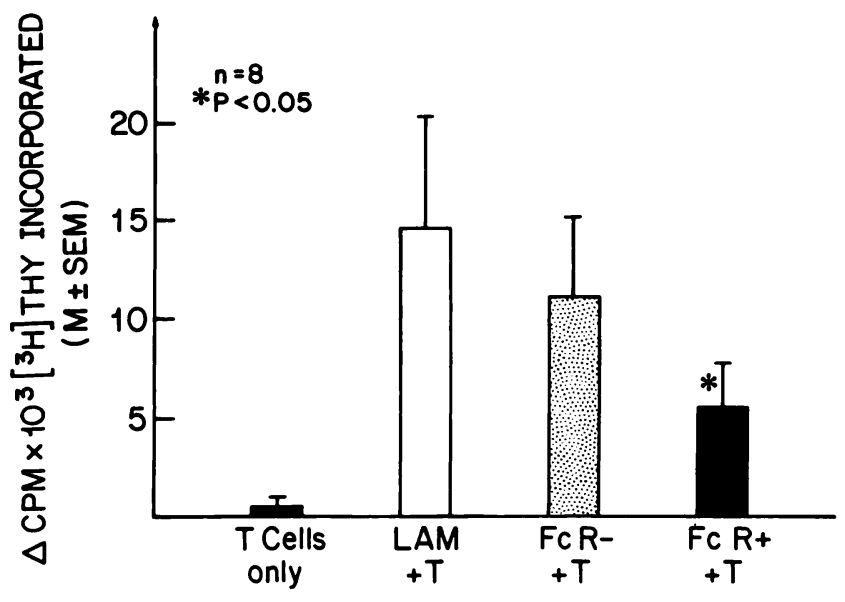

Fig. 4. Comparison of LAM, FC receptor-depleted (FCR-), and Fc receptor-enriched (FCR+) LAM in supporting antigeninduced $\mathbf{T}$ lymphocyte prollferation. Autologous $\mathbf{T}$ cells $\left(10^{5} /\right.$ well) were cultured in triplicate for 6 days with or without $25 \times 10^{3}$ APC. LAM and FCR- cells were not significantly different from one another. $\triangle$ CPM induced by FCR + cells was significantly less than the $\triangle C P M$ induced by LAM $(P<0.05)$.

was not statistically different from that induced by unfractionated LAM. This was largely explained by the large autologous mixed leukocyte reaction (AMLR) induced by FcR - cells (see Fig. 5). The total lymphoproliferation (AMLR + antigen-specific proliferation) induced by $\mathrm{FcR}$ - cells was significantly greater than that of LAM. The removal of FcR + cells from the LAM did not reduce the ability of LAM to present antigen, and FcR - cells were more potent on a cellfor-cell basis than FcR + cells, suggesting that a nonmacrophage cell was primarily responsible for APC function.

\section{Comparison of PMC Fractions in Stimulating an AMLR}

The appearance of an increased AMLR in the FcRfraction of LAM was an additional indication that a potent accessory cell was present in this fraction. It is thought that the AMLR represents a physiologic interaction between resting $\mathrm{T}$ lymphocytes and autologous APC and is required to activate resting lymphocytes in vivo [12]. We compared the ability of various PMC fractions with Mo for their ability to stimulate autologous resting T cells (Fig. 5). Unfractionated PMC were two times and LAM were three times more effective than $M o$ in inducing an AMLR. As previously mentioned, FcR + cells isolated from LAM were significantly less effective than unfractionated LAM in this regard but similar to Mo, while FcR - cells were three times better than $\mathrm{FCR}+$ cells in stimulating an AMLR. When AM were added to autologous $\mathrm{T}$ cells, the proliferation induced 


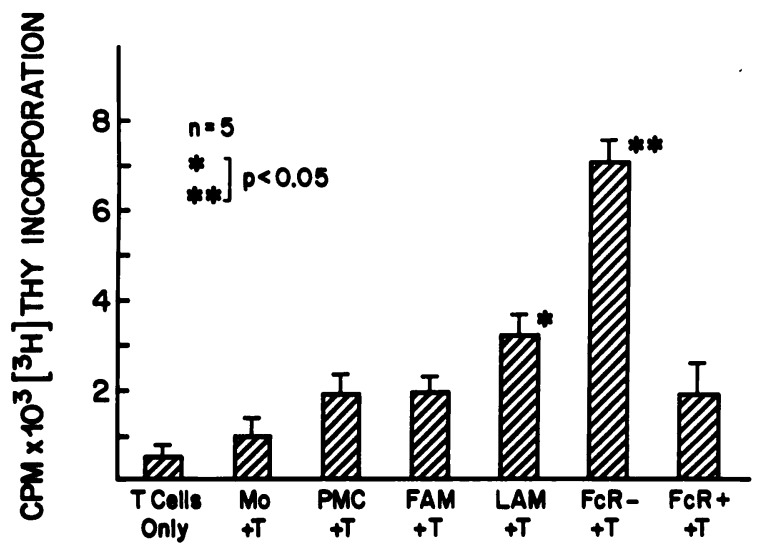

Fig. 5. Response of autologous T cells to Mo, PMC, FAM, LAM, FCR-, or FCR + enriched LAM. Autologous T cells (105/well) were cultured for 6 days with or without $2.5 \times 10^{4}$ APC/well. APC cultured alone demonstrated the following CPM: PMC = $853 \pm 325 ;$ FAM $=789 \pm 234$; LAM $=247 \pm 89 ;$ Mo $=332 \pm 146$; FCR- = $402 \pm 122 ; \mathrm{FCR}+=301 \pm 125 \mathrm{CPM}$. LAM induced a higher AMLR than either PMC, FAM, or FCR + $\left({ }^{*} P<0.05\right)$. Furthermore, the AMLR induced by FCR - was significantly higher than the AMLR produced by all other populations $(* * P<0.05)$.

was not significantly increased compared to the $\mathrm{T}$ cells alone in media with respectively $830 \pm 230 \mathrm{CPM}$ and $621 \pm 234 \mathrm{CPM}(\mathrm{n}=3)$.

\section{Effect of Depleting Phagocytic Macrophages From LAM}

To assess further whether the APC responsible for antigen presentation and AMLR induction was a macrophage, we depleted macrophages from the LAM population by allowing them to ingest silica. Phagocytic cells were removed from LAM by density gradient sedimentation of the silica-ingesting cells. Despite the removal of phagocytic macrophages, the poorly phagocytic cells (Sil-) which floated on the density gradient were equal to LAM in supporting antigen-induced proliferation (Fig. 6A). In addition, the autologous MLR produced by the Sil- population was increased when compared to the LAM (Fig. 6B). Thus the removal of phagocytic cells from LAM did not result in a loss of APC function, again suggesting that a nonmacrophage cell was responsible for stimulating $\mathrm{T}$ lymphocyte proliferation.

\section{Phenotypic Characteristics of LAM}

We next sought to characterize the APC in the LAM fraction and compare it to a population of classical alveolar macrophages (BAL) using a panel of monoclonal antibodies (Table 3). As in prior studies [29], the majority of LAM and BAL were HLA-DR positive. However the antigen $\mathrm{PAM}_{1}$, specific for AM, was found on only $17 \%$ of the LAM but was present on $67 \%$ of cells in BAL. $\mathrm{Mo}_{2}$, specific for Mo, was found on a minority of LAM. These results further support the presence of an APC other than a Mo in LAM, and suggest that AM comprise only a minority of the LAM cells. The lack of staining with the other monoclonals utilized suggested that the majority of LAM were cells other than endothelial cells, B cells, or Langerhans cells.

\section{DISCUSSION}

Although we had previously isolated accessory cells from human lung parenchyma $[29,41]$, prior studies had failed to demonstrate the presence of an antigen-presenting cell. Because the presentation of foreign antigen is likely to occur physiologically, the major importance of the current study was to establish the presence of a cell within the lung with the capacity to stimulate antigen specific lymphoproliferation. Thus, a potent APC, not obtained by bronchoalveolar lavage or by mechanical digestion alone [41], was recovered by mincing and enzymatically digesting human lung. These results both confirm and extend previous studies concerning pulmonary APC.

Cells obtained from the air spaces by bronchoalveolar lavage were ineffective APC, as previously reported $[6,37,40,41]$. It should be noted that a recent report demonstrated that a minor subset of cells within the AM population were effective APC [7]. Several explanations for the poor antigen-presenting capacity by the majority of lavage cells exist. While AM bear HLA-D region antigens $[22,40]$, they may release less IL-1 than Mo $[7,41]$ and suppress antigen-induced proliferation $[5,37]$. A major factor may be that AM bind T cells less effectively than Mo and have a decreased density of LFA-1 [23], suggesting they have altered membrane characteristics that interfere with the physical interaction required for activation of resting $T$ cells. Indeed, using a system which may passively increase T cells - APC contact (round-bottom wells), low numbers of AM were shown to function as well as Mo as accessory cells [32].

The presence of a potent accessory cell in the lung was previously suggested in studies where unfractionated pulmonary mononuclear cells obtained from minced human lung were comparable to Mo in their ability to support an MLR. However, antigen presentation by these cells was no better than antigen presentation by AM [41]. The current findings are best explained by an increased yield of interstitital cells utilizing enzymatic digestion of lung tissue [13]. It is also possible that mechanical digestion preferentially obtains airway cells which act as suppressors of antigen presentation. Incubation of AM and Mo in collagenase and elastase under similar conditions did not result in increased $T$ cell 


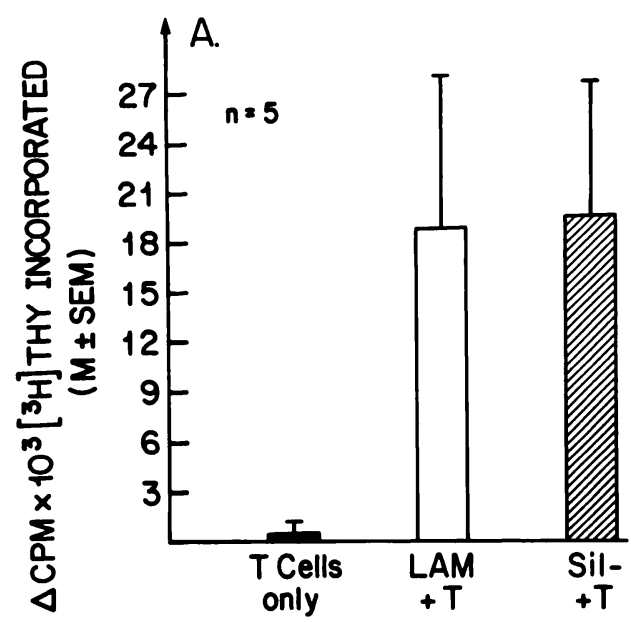

Fig. 6. Comparison of LAM and nonphagocytic LAM (Sil-) in supporting antigen-induced $T$ lymphocyte proliferation (A) or in stimulating autologous $T$ lymphocytes (B). Autologous $T$ cells $\left(10^{5} /\right.$ well) were cultured with or without $2.5 \times 10^{4} \mathrm{APC} /$ well. Both graphs express the results of five experiments \pm SEM.

TABLE 3. Phenotype of LAM and AM"

\begin{tabular}{lccc}
\hline $\begin{array}{l}\text { Monoclonal } \\
\text { antibody }\end{array}$ & Specificity & LAM & BAL \\
\hline L243 & HLA-DR & $93 \pm 3$ & $96 \pm 2$ \\
PAM $_{1}$ & Alveolar macrophage & $17 \pm 2.8$ & $67 \pm 12$ \\
Mo $_{2}{ }^{\text {c }}$ & Monocytes & $15 \pm 2.6$ & $14 \pm 5$ \\
OKT6 $^{\text {b }}$ & Langerhan's cell & $<1$ & N.D. \\
DRC $_{1}$ & Follicular DC & 0 & N.D. \\
Leu 14 $^{\text {b }}$ & B lymphocyte & $<1.5$ & N.D. \\
Anti-Factor VIII & Endothelial cell & $<2$ & N.D. \\
\hline
\end{tabular}

${ }^{a}$ Cells from at least 4 subjects were isolated and analyzed by indirect immunofluorescence as described in Materials and Methods. Results indicate percent positive cells.

${ }^{b}$ For completeness these data are included, but have been previously published [29].

${ }^{\mathrm{C}} \mathrm{Mo}_{2}$ was expressed on $90 \%$ of adherence purified peripheral blood monocytes.

${ }^{d}$ Anti-Factor VIII was present on $>\mathbf{9 5 \%}$ of control endothelial cells.

proliferation [29]. Thus, it is unlikely that enzyme treatment of PMC had a direct effect on accessory cell function. It is possible that in occasional normal volunteers $[23,37]$ and in sarcoid patients when BAL present antigen as effectively as Mo $[21,40]$ that APC normally located in the interstitium $[3,26]$ increase in the alveolus, becoming accessible to lavage.

The present studies have demonstrated several important characteristics of the APC obtained from minced lung which distinguishes them from Mo or AM. LAM were more effective than Mo in supporting antigeninduced $T$ cell proliferation. In addition, the majority of LAM have a phenotype which differed from both AM or

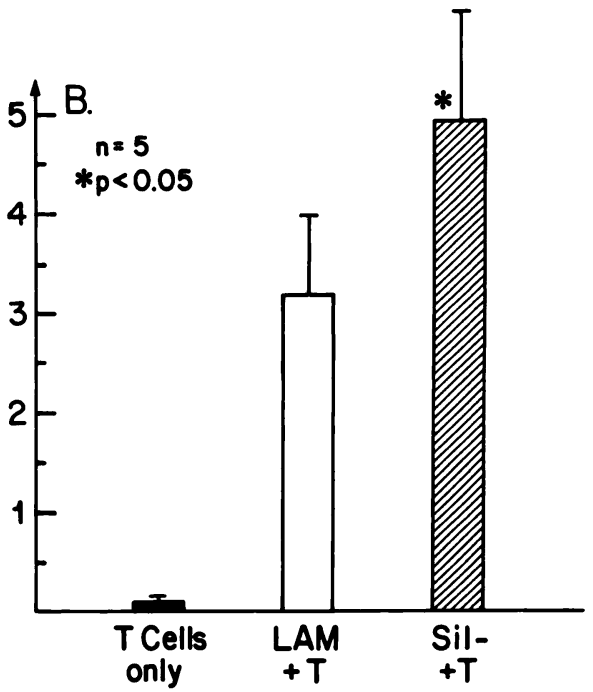

Antigen presentation by Sil- was not different from LAMinduced T lymphocyte proliferation with mumps. The AMLR produced in the absence of antigen was enhanced with Silcompared to $L A M$-induced $T$ cell proliferation ( $\left.{ }^{*} P<0.05\right)$.

Mo; i.e., LAM were largely $\mathrm{PAM}_{1}$ and $\mathrm{Mo}_{2}$ negative. Antigen presentation was preserved when $\mathrm{FcR}-$ or nonphagocytic LAM were used as accessory cells and was decreased when FCR + cells were used. Although it is possible that some form of cooperation between macrophage and nonmacrophage cell types is required for optimal antigen presentation, this data would suggest that the number of macrophages necessary for such cooperation is small. Indeed, taken together these observations suggest the cell responsible for antigen presentation in human lung is a cell other than a classical macrophage.

It is noteworthy that antigen presentation induced by either FcR - or Sil - cells was not greater than that induced by LAM alone. One possible explanation for this is that expression of FCR by the nonmacrophage AC may be heterogeneous. Indeed dendritic cells present in murine lung are heterogeneous in regard to FcR expression [34]. The consistently poorer APC function of both FAM and FcR + cells strongly suggests that a cell other than a classical macrophage is responsible for the majority of antigen-specific $T$ cell proliferation. Another explanation for the equivalent amount of proliferation induced by $\mathrm{FcR}-$ and Sil - is that the large AMLR produced by these cells tends to make the demonstration of antigen-specific proliferation more difficult.

FcR - LAM and Sil - LAM demonstrated a significantly enhanced ability to stimulate proliferation of syngeneic $T$ lymphocytes in the absence of known antigen compared to the parent LAM cells. Although 
macrophages, Mo, B, and null cells can stimulate an AMLR, dendritic cells appear to be the most effective stimulator cell for this reaction [4]. Dendritic cells, which are loosely adherent, nonphagocytic, and Fc receptor negative mononuclear cells, thus possess many of the properties of the AMLR stimulating cell in human lung. Therefore, there is a possibility that a DC is also responsible for the antigen-presenting ability of LAM. Indeed, HLA-DR-positive cells similar to dendritic cells have been described in the airway in the interstitium surrounding blood vessels and in the pleura of human lung [34]. Other cells, such as B lymphocytes [9], Langerhans cells [36], endothelial cells [24,30], fibroblasts [8], and Type II pneumocytes [33] could also function as APCs in the lung. The latter three cells must be stimulated by gamma interferon to express class II major histocompatibility antigens $[8,33]$, and the negative staining for B cells, Langerhans cells, and endothelial cells in LAM suggest that none of these cells were the APC in the current study.

Recent work with flow cytometry in our laboratory has demonstrated that the accessory cell function of LAM is enriched in a relatively nonautofluorescent subpopulation [42]. These cells are predominantly nonspecific esterase negative and have a morphology consistent with dendritic cells. We therefore believe that the APC obtained from lung parenchyma is likely a dendritic cell. Nevertheless, further studies are essential to determine the nature of the APC in human lung parenchyma.

The finding that normal lung tissue contains cell(s) which can effectively present antigens is of considerable importance. A major unresolved question is where these cells reside. We believe the majority are likely interstitial, because enzyme digestion is required to recover them. However, the development of a specific cell marker is required in order to locate them in tissue sections. Nevertheless, we postulate that the presence of an APC in the interstitium, with only a minor subpopulation in the alveolus, is critical in preserving the integrity of pulmonary parenchymal tissue. This distribution might help prevent the development of hypersensitivity diseases in the lung in response to inhaled antigens. However, pulmonary APC would function to induce immunity when antigens including microorganisms penetrate the epithelial barrier and gain access to the interstitium.

\section{ACKNOWLEDGMENTS}

The writers wish to acknowledge the cooperation of the Department of Anesthesiology, the Division of Thoracic Surgery, and the Department of Forensic Pathology at the University of Texas Health Science Center at Dallas. We also express our deep appreciation to Jacky Albertson for her technical assistance and to Pattie Pipes for her skillful preparation of the manuscript. This work was supported by National Institutes of Health grants HL 29543, AI 21951, HL 01797, and M01 RR00633.

\section{REFERENCES}

1. Bienenstock, J. Bronchus-associated lymphoid tissue. In Immunology of the Lung and Upper Respiratory Tract, (Bienenstock, J., Ed.) New York: McGraw-Hill, volume 3, p. 96, 1984.

2. Biondi, A., Rossing, T.H., Bennett, J., and Todd, R.F., III. Surface membrane heterogeneity among human mononuclear phagocytes. J. Immunol. 132,1237, 1984.

3. Brain, J.D., Sorokin, S.P., and Godleski, J.J. Quantification, origin, and fate of pulmonary macrophages. In Lung Biology in Health and Disease, Vol. 5, Respiratory Defense Mechanisms, Part II. (Brain, J.D., Proctor, D.F., Reid, L.M., Eds.) New York: Marcel Dekker, Inc., p. 849, 1977.

4. Crow, M.K., and Kunkel, H.G. Human dendritic cells: Major stimulators of the autologous and allogeneic mixed leucocyte reactions. Clin. Exp. Immunol. 49,338, 1982.

5. Ettensohn, D.B., Lalor, P.A., and Roberts, N.J., Jr. Human alveolar macrophage regulation of lymphocyte proliferation. Am. Rev. Respir. Dis. 133,1091, 1986.

6. Ettensohn, D.B., and Roberts, N.J., Jr. Human alveolar macrophage support of lymphocyte responses to mitogens and antigens. Analysis and comparison with autologous peripheral-bloodderived monocytes and macrophages. Am. Rev. Respir. Dis. 128,516, 1983.

7. Ferro, T.J., Kern, J.A., Elias, J.A., Kamoun, M., Daniele, R.P., and Rossrian, M.D. Alveolar macrophages, blood monocytes, and density-fractionated alveolar macrophages differ in their ability to promote lymphocyte proliferation to mitogen and antigen. Am. Rev. Respir. Dis. 135,682, 1987.

8. Geppert, T.D., and Lipsky, P.E. Antigen presentation by interferon-gamma-treated endothelial cells and fibroblasts: differential ability to function as antigen-presenting cells despite comparable Ia expression. J. Immunol. 135,3750, 1985.

9. Glimcher, L.H., Kim, K., Green, I., and Paul, W.E. Ia antigenbearing $\mathbf{B}$ cell tumor lines can present protein antigen and alloantigen in a major histocompatibility complex-restricted fashion to antigen-reactive T cells. J. Exp. Med. 155,445, 1982.

10. Green, G.M., Jakab, G.J., Low, R.B., and Davis, G.S. Defense mechanisms of the respiratory membrane. Am. Rev. Respir. Dis. $155,245,1977$.

11. Grey, H.M., and Chesnut, R. Antigen processing and presentation to T cells. Immunol. Today 6,104, 1985.

12. Hausman, P.B., and Stobo, J.D. Specificity and function of a human autologous reactive T cell. J. Exp. Med. 149,1537, 1979.

13. Holt, P.G., Degebrodt, A., Venaille, T., O'Leary, C., Krska, K. Flexman, J., Farrell, H., Shellam, G., Young, P., Penhale, J., Robertson, T., and Papadimitriou, J.M. Preparation of interstitial lung cells by enzymatic digestion of tissue slices: preliminary characterization by morphology and performance in functional assays. Immunology 54,139, 1985.

14. Hunninghake, G.W., Garrett, K.C., Richerson, H.B., Fantone, J.C., Ward, P.A., Rennard, S.I., Bitterman, P.B., and Crystal, R.G. Pathogenesis of the granulomatous lung diseases. Am. Rev. Respir. Dis. 130,476, 1984. 
15. Jones, P.D., and Ada, G.L. Influenza virus-specific antibodysecreting cells in the murine lung during primary influenza virus infection. J. Virol. 60,614, 1986.

16. Kaltreider, H.B., Caldwell, J.L., and Byrd, P.K. The capacity of normal murine alveolar macrophages to function as antigenpresenting cells for the initiation of primary antibody-forming cell responses to sheep erythrocytes in vitro. Am. Rev. Respir. Dis. $133,1097,1986$.

17. Kaltreider, H.B., Curtis, J.L., and Arraj, S.M. The mechanism of appearance of specific antibody-forming cells in lungs of inbred mice after immunization with sheep erythrocytes intratracheally. II. Dose-dependence and kinetics of appearance of antibody-forming cells in hilar lymph nodes and lungs of unprimed and primed mice. Am. Rev. Respir. Dis. 135,87, 1987.

18. Kobzik, L., Godleski, J.J., Biondi, A., O'Hara, C.J., and Todd, R.F., III. Immunohistologic analysis of a human pulmonary alveolar macrophage antigen. Clin. Immunol. Immunopathol. 37,213, 1985.

19. Lampson, L.A., and Levy, R. Two populations of Ia-like molecules on a human B cell line. J. Immunol. 125,293, 1980.

20. Leatherman, J.W., Michael, A.F., Schwartz, B.A., and Hoidal, J.R. Lung $T$ cell in hypersensitivity pneumonitis. Ann. Intern. Med. 100,390, 1984.

21. Lem, V.M., Lipscomb, M.F., Weissler, J.C., Nunez, G., Ball, E.J., Stastny, P., and Toews, G.B. Bronchoalveolar cells from sarcoid patients demonstrate enhanced antigen presentation. J. Immunol. 135,1766, 1985.

22. Lipscomb, M.F., Lyons, C.R., Nunez, G., Ball, E.J., Stastny, P., Vial, W., Lem, V., Weissler, J., Miller, L.M., and Toews, G.B. Human alveolar macrophages: HLA-DR-positive macrophages that are poor stimulators of a primary mixed leukocyte reaction. J. Immunol. 136,497, 1986.

23. Lyons, C.R., Ball, E.J., Toews, G.B., Weissler, J.C., Stastny, P., and Lipscomb, M.F. Inability of human alveolar macrophages to stimulate resting $\mathrm{T}$ cells correlates with decreased antigenspecific $T$ cell-macrophage binding. J. Immunol. 137,1173, 1986.

24. Malissen, B., Price, M.P., Goverman, J.M., McMillan, M., White, J., Kappler, J., Marrack, P., Pierres, A., Pierres, M., and Hood, L. Gene transfer of $\mathbf{H}-2$ class II genes: antigen presentation by mouse fibroblast and hamster B-cell lines. Cell 36,319, 1984.

25. Mason, M.J., Bice, D.E., and Muggenburg, B.A. Local pulmonary immune responsiveness after multiple antigenic exposures in the cynomolgus monkey. Am. Rev. Respir. Dis. 132,657, 1985.

26. McDermott, M.R., Befus, A.D., and Bienenstock, J. The structural basis for immunity in the respiratory tract. Int. Rev. Exp. Pathol. 23,47, 1982.

27. Miossec, P., Cavender, D., and Ziff, M. Production of interleukin 1 by human endothelial cells. J. Immunol. 136,2486, 1986.

28. Moreno, J., and Lipsky, P.E. Differential ability of fixed antigenpresenting cells to stimulate nominal antigen-reactive and alloreactive T4 lymphocytes. J. Immunol. 136,3579, 1986.
29. Nicod, L.P., Lipscomb, M.F., Weissler, J.C., Lyons, C.R., Albertson, J., and Toews, G.B. Mononuclear cells in human lung parenchyma: characterization of a potent accessory cell not obtained by bronchoalveolar lavage. Am. Rev. Respir. Dis. 136, $818,1987$.

30. Nunez, G., Ball, E.J., and Stastny, P. Accessory cell function of human endothelial cells. I. A subpopulation of la positive cells is required for antigen presentation. J. Immunol. 131,666, 1983.

31. Raff, H.V., Picker, L.J., and Stobo, J.D. Macrophage heterogeneity in man: A subpopulation of HLA-DR bearing macrophages required for antigen-induced $T$ cell activation also contains stimulators for autologous-reactive $\mathrm{T}$ cells. J. Exp. Med. $152,581,1980$.

32. Rich, E.A., Tweardy, D.J., Fujiwara, H., and Ellner, J.J. Spectrum of immunoregulatory functions and properties of human alveolar macrophages. Am. Rev. Respir. Dis. 136,258, 1987.

33. Schneeberger, E.E., DeFerrari, M., Skoskiewicz, M.J., Russell, P.S., and Colvin R.B. Induction of MHC-determined antigens in the lung by interferon gamma. Lab. Invest. 55,138, 1986.

34. Sertl, K., Takemura, T., Tschachler, E., Ferrans, V.J., Kaliner, M.A., and Shevach, E.M. Dendritic cells with antigen-presenting capability reside in airway epithelium, lung parenchyma, and visceral pleura. J. Exp. Med. 163,436, 1986.

35. Steinman, R.M., Kaplan, G., Witmer, M.D., and Cohn, Z.A. Identification of a novel cell type in peripheral lymphoid organs of mice. V. Purification of spleen dendritic cells, new surface markers, and maintenance in vitro. J. Exp. Med. 149,1, 1979.

36. Stingl, G., Katz, S.I., Clement, L., Green, I., and Shevach, E.M. Immunologic functions of Ia-bearing epidermal Langerhans cells. J. Immunol. 121,2005, 1978.

37. Toews, G.B., Vial, W.C., Dunn, M.M., Guzzetta, P., Nunez, G., Stastny, P., and Lipscomb, M.F. The accessory cell function of human alveolar macrophages in specific $\mathrm{T}$ cell proliferation. $\mathrm{J}$. Immunol. 132,181, 1984.

38. Unanue, E.R., and Allen, P.M. The basis of the immunoregulatory role of macrophages and other accessory cells. Science 236,551, 1987.

39. VanVoorhis, W.C., Valinsky, J., Hoffman, E., Luban, J., Hair, L.S., and Steinman, R.M. Relative efficacy of human monocytes and dendritic cells as accessory cells for $\mathrm{T}$ cell replication. J. Exp. Med. 158,174, 1983.

40. Venet, A., Hance, A.J., Saltini, C., Robinson, B.W.S., and Crystal, R.G. Enhanced alveolar macrophage-mediated antigeninduced T lymphocyte proliferation in sarcoidosis. J. Clin. Invest. 75,293, 1985.

41. Weissler, J.C., Lyons, C.R., Lipscomb, M.F., and Toews, G.B. Human pulmonary macrophages. Functional comparison of cells obtained from whole lung and by bronchoalveolar lavage. Am. Rev. Respir. Dis. 133,473, 1986.

42. Nicod, L, Lipscomb M., Toews G., and Weissler J.C. Separation of potent and poorly functional human lung accessory cells based on autofluorescence J. Leukocyte Biol. In Press. 